\title{
Youths and Fashion: Is ICT A Yardstick? A Case Study of University of Maiduguri
}

\author{
Yusuf IU and Umar MA*
}

Department of Mass Communication, University of Maiduguri, Nigeria

\begin{abstract}
The emergence of Information and Communication Technology has brought about a paradigm shift from local to modernized way of doing things. It has touched virtually all aspect of people's life socially, politically and economically. This study titled 'Youths and Fashion: is ICT a yardstick?', seeks to find out whether the use of ICTs and internet have improve people's access to fashion styles; find out the channels through which people access fashion using ICTs and the internet, and also to figure out if there are enticements that led to changes in how people adopt fashion styles. Two theories diffusion of Innovation and Process Virtualization Theory were considered relevant for the study. Findings revealed that the use of ICT and internet does not limit to chatting and mingling with friends online but also used in accessing desired product and services. $92 \%$ of the respondents who believed that ICT has improved accessibility to various modern and qualitative fashion designs. $86 \%$ of the respondents affirmed that there are online platforms where fashion styles and designs are found and that they access them for their consumption. The study found that two (2) social networking sites (Facebook and WhatsApp) constituted the highest percentage and most used platforms for accessing and sharing of fashion related materials.
\end{abstract}

Keywords: ICT; Fashion; Digital telecommunications; Internet

\section{Introduction}

Information and Communication Technology (ICT) is an acronym for collection of technologies used for passing information and enhancing communication. Its emergence and later surge as well as impact on various aspects of people's life have been identified as one of the major drivers of globalization. Arguably, ICTs have touched virtually every aspect of individual, group and national development of countries. According to Igbo et al. [1] "Information and Communication Technologies come in different forms and types ranging from the conventional mass media (radio, television, video, tape recorder) to more recent ones like computers, cell phones, e-mails, World Wide Web (www), interactive multimedia system and digital telecommunications". Every type of the ICT has a peculiar role in the social change of the society especially how youth embrace them in their daily lives. It is on this note however that Igbo et al. went further to argue that:

It is a common scenario now to see most Nigerian youths have access and make use of one or more of the ICT gadgets. In Nigeria today, practically every youth lives in a home equipped with the basic tools of the information age including radio, television, telephone, $D V D$, video cassette recorders and cell phones. The cell phone and the computer are central appliances of the media culture that will in time converge with digital television. Personal observations have shown that cell phones have gradually become part of everyday life of youths in the society. Some undergraduate students have either desktop or laptop computers in their homes. Accessibility to the computer has been made much easier by the introduction and establishment of cyber cafes in most streets in the urban areas. This gives youth's adequate opportunities to access the internet with little money. Most of these cyber cafes operate on a 24 hour basis allowing some youths to spend the night with them. This behavior might lead to internet addiction and lateness to lectures for such students.

The lines of arguments above reflected the invariable role of information and communication technology in changing the way youth conduct their daily lives regardless of urban or rural areas provided that the access is guaranteed. The impact of ICTs on social life such as relations with families, friends, peer groups, sport, relationship, romance, gaming, fashion, sexuality, shopping, unionism and host of others has become very enormous.

It is a common saying that nothing is constant like change. However, change comes in various shapes, nature and angles. There are also types of change ranging from economic, religious, political and social change. According to a sociologist Wilterdink [2] social change refers to the alteration of mechanisms within the social structure, characterized by changes in cultural symbols, rules of behavior, social organizations or value systems. Considering the changes brought by the ICT Wilterdink definition has not covered issues of pattern of behavior, emergence of new social conduct by youths and shrinking of space in terms of relationships and interactions. Relationships that previously were established and sustained mainly through face-to-face interaction have come to be complemented by a social technology that is creating a new type of interpersonal relationship.

The major forced in the social change pulled by ICT is enormously moved by the internet. The internet is what connect and establish channels and lines of communications using the ICTs. The emergence of internet has led to greater changes in societal conduct and behavioral relationship. This is tune with the assertion of Shim cited in Gapsiso and Wilson [3] that internet is fundamentally changing human communication. From a traditional means to a modern and technologically driven means internet has shrunk the gap between people of different locales, race, gender, nationals and ideologies. Apart from communication and relationships, the internet and ICT gadgets have also improve the access to daily needs of people. Nonetheless, the impacts on various aspects are exclusive and distinct.

*Corresponding author: Umar MA, Department of Mass Communication University of Maiduguri, Nigeria, Tel: 08136464011; E-mail: muhammadauwal32@gmail.com

Received June 09, 2018; Accepted July 23, 2018; Published July 30, 2018

Citation: Yusuf IU, Umar MA (2018) Youths and Fashion: Is ICT A Yardstick? A Case Study of University of Maiduguri. J Mass Communicat Journalism 8: 379. doi: 10.4172/2165-7912.1000379

Copyright: (C) 2018 Yusuf IU, et al. This is an open-access article distributed under the terms of the Creative Commons Attribution License, which permits unrestricted use, distribution, and reproduction in any medium, provided the original author and source are credited. 
One of the most trending and fast developing aspect of youth's life is fashion and dressing. It has grown worldwide to be a strong industry worth billions of dollars. Nigeria is not an exception in the trend. This is propelled by the adoption of ICTs at the levels of design, production, advert, marketing and distribution of the fashion designs and equipments. Several platforms on the internet (social media in particular) were created and dedicated to publicizing and modeling fashion designs as well as fashion tools for ladies. Nowadays, youth do not have follow delayed channels of being exposed to latest fashion designs and tools. It has been brought to the fingerprint of youth wherever they are provided that they can access the internet using their one or more ICT gadgets. The development has also provided companies with opportunities to sell their fashion products online (online marketing) without a physical contact with customers.

It is no more a strange thing to see American new fashion styles and designs being emulated in Nigeria within shortest possible time. These are products of ICT impact on enhancing the accessibility to such things on social media platforms. To this end, the social way of fashion has enormously changed and experienced paradigm shift in most of its ramifications. Before the surge of ICT, social media and internet, development in such aspect are delayed and hardly communicated to larger audience, unlike now that everybody is a potential consumer. The depth of social media in the development and diffusion of fashion as well as the significant changes brought will take the center stage of the discussion of this work

No doubt, the term ICT is broad thus covering it becomes difficult. It is on this background that this paper focuses more on the internet and social media as twin component of the Information and Communication technology. The social media are faster in diffusion of fashion styles and tool.

\section{Statement of Problem}

Remarkably, information and communication technology has altered so many traditions and conduct in the social life of people regardless of country, tribe, culture, ethnic or religious diversity. The adjustment can be seen from both positive and negative angles when issues of religion and culture are raised. Nonetheless, the overriding impact on social life is positive and enormous because it guaranteed freedom for direct consumers to have access, select and adopt latest development. Fashion is one of the areas of interest identified by this study. How have the ICT and the internet change fashion lifestyle of people? What are the enticements that led to such changes? What is the frequency of adoption among the people? What are the channels of access? These are the rhetoric questions that prompted the conduct of this study.

\section{Objectives of the Study}

The study is aimed at attaining the following objectives:

i. To find out whether the use of ICTs and internet has improve people's access to fashion styles.

ii. To find out the channels through which people access fashion using ICTs and the internet.

iii. To figure out if there are enticements that led to changes in how people adopt fashion styles.

iv. To determine how often people access fashion styles using the ICTs.

v. To determine whether the use of ICT and internet has decreased their desire for offline fashion style.

\section{Research Questions}

i. Has the use of ICTs and internet improved people's access to fashion styles?

ii. Are there channels through which people access fashion using ICTs and the internet?

iii. What are the enticements that led to changes in how people adopt fashion styles?

iv. How often people access fashion styles using the ICTs?

v. Has the use of ICT and internet decreased their desire for offline fashion style?

\section{Literature Review}

The term ICT stands for Information and communication technologies which are a broader collection of all technical ways of collecting, arranging, and processing as well as diffusion of information. The term has gained popularity partially due to the convergence of information technology (IT) and telecom technology. ICT defines a broad range of technologies, including methods for communication (communication protocols, transmission techniques, communications equipment, media communication), as well as techniques for storing and processing information (computing, data storage etc). They are often associated with high-tech devices, such as computers and software, but ICT also encompasses more "conventional" technologies such as radio, television and telephone technology [3]. The scholars further refer to ICT as forms of technology that are used to transmit, store, create, share or exchange information. This broad definition of ICT includes such technologies as: radio, television, video, DVD, telephone (both fixed line and mobile phones), satellite systems, computer and network hardware and software; as well as the equipment and services associated with these technologies, such as videoconferencing and electronic mail [3].

Several scholars have written on the development and impact of Information and Communication technology. Internet is a strong component and center stage of interconnecting the ICTs. The interconnections are what make ICTs viable in enhancing social life of users. This is why Gapsiso and Wilson stated that the Internet has not only expanded our understanding of human interaction, our meaning of the word community, and our social network but has also expands our horizons, minds, and capabilities to organise new ways to incorporate our offline experiences into cyberspace. Adigwe complemented the argument by asserting that "Information and Communication Technology has transformed the world in all spheres of life.....its potential for reducing manual operations and fostering growth has increased rapidly".

However, social media is a strong phenomenon in these lines of arguments and assertions. Social media is used to describe a set of online tools that enable interactions among people to build relationships and share information. Dewing [4] put that social media refers to the wide range of internet-based and mobile service that allow users to participate in online exchanges, contribute usercreated content or join online communities. It provides a quick way to communicate information to a wide audience, and to solicit audience input and feedback. Social media tools are vast, and new ones are constantly being created. The most popular and widely used social media tools include: Facebook, Twitter, YouTube, Google etc. Dewing [4] outlined blogs, wikis, social networking sites, social bookmarking, virtual world content and media-sharing sites as internet services 
associated to social media. These are the tools people frequently use to promote and facilitate web-based social interaction. Each social media tool has its strengths and weaknesses, and some are better used for certain purposes than others. For instance, Twitter is useful for promoting your work to a larger audience whereas the Facebook Page is a great tool for engaging creating news interactions, relationship and sustaining the existing ones [5].

While commenting on the peculiar attributes of social media Dewing [4] states that: With attributes that can affect the way people interact online, social media open up new ways for collaborations and discussions. One of these is persistence, meaning that a great deal of content posted on social media sites may remain permanently by default. Other characteristic are replicability (content can be copied and shared) and search ability (content can be found easily using online search tools).

The characteristic of accessibility is also important. Social media can be used anywhere, at any time where an internet connection is available. These attributes shape the dynamics of social interaction online [6].

Moreover, just as it is difficult to know who might be reading content posted on a social media site, the identity and motives of those who post content are not always clear. For example there have been instances of companies using social media to market product through fake blogs or sponsored postings on social media sites [7].

Change according to sociologist Shah [8] is the law of nature. The social structure is subject to incessant change. Individuals may strive for stability, societies may create illusion of permanence, the quest for certainty may continue unabated hitherto the fact remains that society is an ever-changing phenomenon, growing, decaying, renewing and accommodating itself to changing conditions and suffering vast modifications in the course of time [8].

Social change is single part of these changes that happen to societies. Several scholars have distinct angular look at the definition of social change. Mazumdar defined it as a new fashion or mode, either modifying or replacing the old, in the life of a people, or in the operation of a society. Another sociologist that defined the term is Lundberg who stated that social change refers to any modification in established patterns of inter human relationships and standards of conduct. There are core attributes that signal social change. These are identified by Shah as: universal in nature; it happens within communities; social change is not uniform; nature and speed of social change is affected by and related to time factor; social change occurs as an essential law; definite prediction of social change is not possible; social change results from the interaction of a number of factors (Figure 1).

The study is anchored on the Diffusion of Innovation theory and Process Virtualization Theory (PVT).

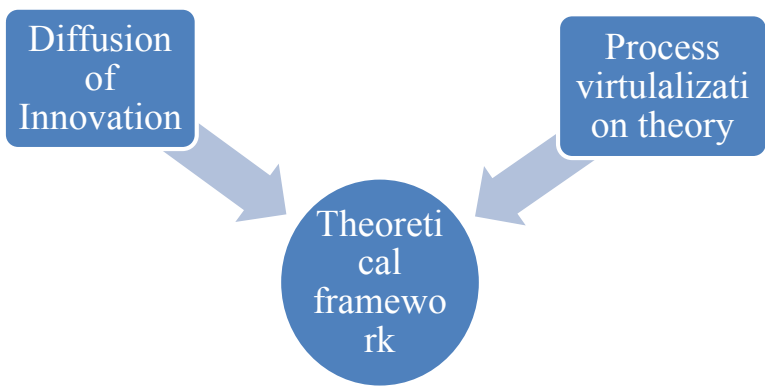

Figure 1: Theoretical framework.
Diffusion of Innovation theory was propounded by Everett Rogers in 1962. The theory seeks to explain how, why, and at what rate new ideas and technology spread. Rogers argues that diffusion is the process by which an innovation is communicated over time among the participants in a social system. For Rogers, adoption is a decision of "full use of an innovation as the best course of action available" and rejection is a decision "not to adopt an innovation". Rogers defines diffusion as "the process in which an innovation is communicated thorough certain channels over time among the members of a social system". As expressed in this definition, innovation, communication channels, time, and social system are the four key components of the diffusion of innovations. Diffusion research centers on the conditions which increase or decrease the likelihood that a new idea, product, or practice will be adopted by members of a given culture. Diffusion of innovation theory predicts that media as well as interpersonal contacts provide information and influence opinion and judgment.

The Process Virtualization Theory was proposed on the basis of continuous variable describing how amenable a process is to being conducted without physical interaction between people or between people and objects. Overby [9] states that the major tenet of the theory presumes that in our increasingly virtual society, more and more processes that have traditionally been conducted via physical mechanisms are being conducted virtually. The "process virtualization" happens in many contexts which include: formal education (E-Learning), shopping (E-commerce), and friendship development among others. Fashion is one of the contextual aspects that have been virtualized through the information and communication technologies specifically diffused through social networking sites (social media) and other forums.

The theory also propagated factors that explicitly underscore the theoretical significance of information technology in process virtualization by discussing the moderating effects of representation, reach, and monitoring capability. This helps explain how advances in information technology are enabling a new generation of virtual process. The theory was selected because its core assumption came in consonance with the direction of this study with respect to ICT being a driving force in the process of visualizing social conduct of the society which fashion is one. The ways in which ICT help in visualizing the diffusion, adoption and importation fashion styles cannot be overemphasized.

\section{Methodology}

The study used survey as methodology for conducting the research. Survey implies the selection of portion of a particular population to be studied which adequately represent the universe. This study purposely sampled 50 Undergraduate ( 25 males and 25 females) Students of the University of Maiduguri, Borno State.

The study used questionnaire as a tool for collecting data. Questionnaire is set of questions deliberately designed to inquire data from respondents. The questionnaire was self-administered targeted at students on campus. The undergraduate students were considered apt for this research probing the impact of information and communication technology on social life of people: a case study of fashion because most of the students are ICT savvies and have access to ICT (such as mobile phone, computers, internet, social networking sites etc). The purposive sampling considered three attributes before selecting respondent. These attributes are: ownership and access to ICT gadgets, access to the internet and using social networking sites. 


\section{Data presentation and analysis}

Out of the (50) questionnaire administered only two copies were not retrieved (i.e., only forty eight (48) were used for the presentation and analysis. This was achieved because the researcher took time to interact with the respondents to ensure that their attribute met the purposive selection of the study. The presentation used quantitative and qualitative method. This is because the quantification was used for counting number of respondents from item 1-13 while the qualitative was deployed to aid the analysis of the last item, which is open-ended question. Results and discussion of findings are presented based on the objectives of the study (Figure 2).

The above chart indicated that all the sampled respondents met the attribute suitable for the study. This was established by the $48(100 \%)$ of the respondents having access to the internet. Since all of them are undergraduates of the University of Maiduguri, they have access to ICTs and internet amenities either at ICT center, other cafes on campus or their mobile devices (Figure 3).

From the above, it is evident that greater number of the respondent 37 (77\%) accesses the internet using mobile devices. There are $4(8 \%)$ respondents who use Tablets and Ipads to access the internet. Even though, tablets and Ipadss are mobile devices but they are a bit different from mobile phones. Only 7 (15\%) use computers to access the internet. This indicates how mobile devices were enormously admired by the respondents as ICTs used to access the internet (Figure 4).

From the above, the entire respondents have frequency of time spent using the internet. Highest number of the respondents $14(29 \%)$ used the internet for two (2) hours daily. There are 7 (15\%) respondents who use the internet 1 hour daily and same number was obtained from

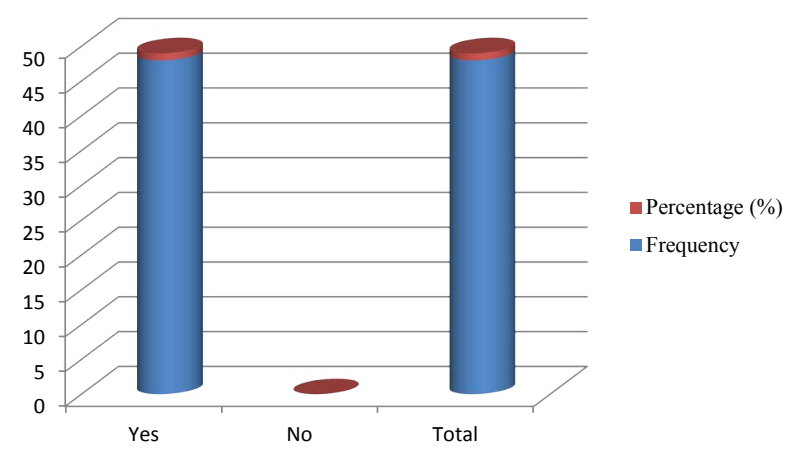

Figure 2: Internet access.

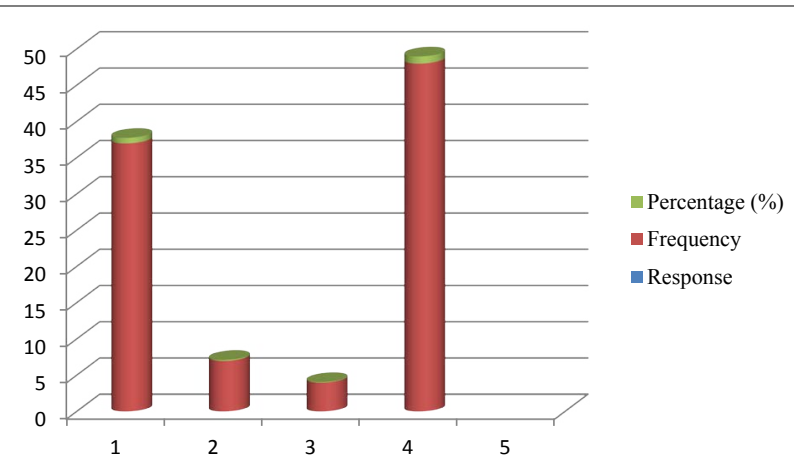

Figure 3: ICT gadget used for accessing Internet.

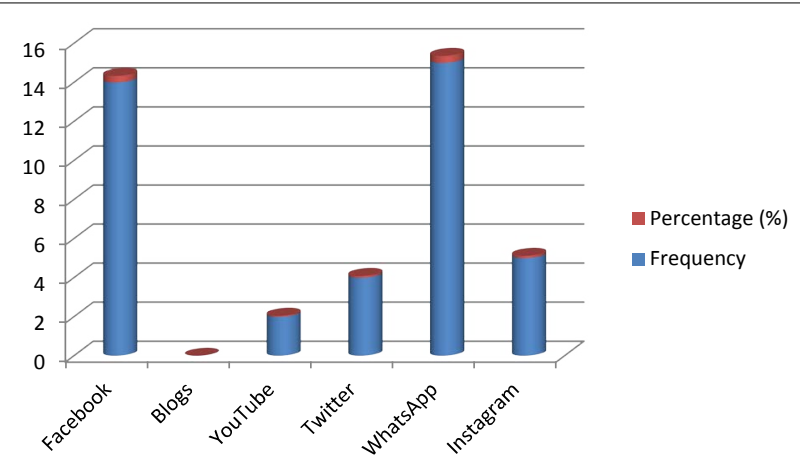

Figure 4: Frequency of online presence.

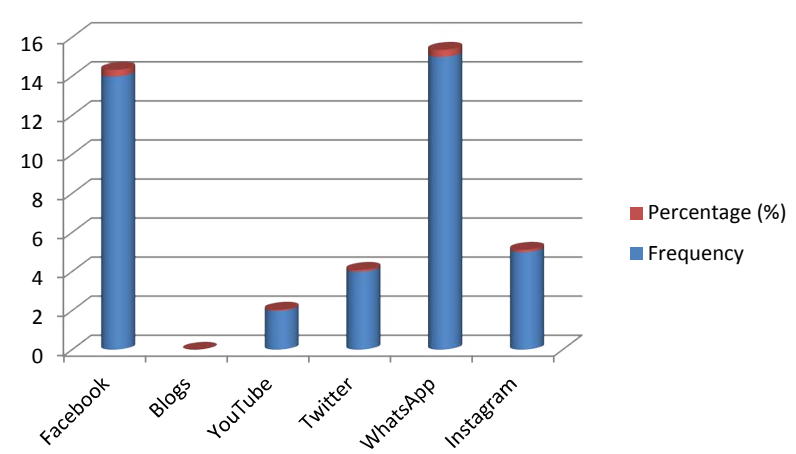

Note: some respondents made multiple choices to indicate that they use several platforms to access fashion styles of their desire. There are 6 respondents in this respect.

Figure 5: Channels of access to fashion styles.

those who use the internet three (3) hours daily while only 8 (16\%) use the internet for more than five (5) hours daily. This means that the students spend much of time accessing the internet thus decreasing their offline engagements in social affairs (Figure 5).

The above column shows that the respondents have various channels and platforms through which they access fashion designs, styles and tools. The platforms are social media and social networking sites where people interact with each other and share multimedia messages. Facebook and WhatsApp are the most used among the respondents with $14(33 \%)$ and $15(36 \%)$ respectively. Other channels like Twitter, Youtube and Instagram have less number of users in terms of accessing the fashion online. In the same vein, there is no respondent who indicated the use of blogs as channel for such desire. However, 6 respondents identified that they use more than one platform (Figure 6).

From the above column, greater number of the respondents agreed that ICTs and the internet have improved accessibility to fashion styles. This is collectively supported by 44 (92\%) of the respondents. Only 4 $(8 \%)$ of the respondents negated that it has improved their accessibility. That is to say despite the improvement there are still issues with accessibility either from internet connection or lack of knowledge of the channels of access (Figure 7).

The above column presents, response regarding the areas in which the use of ICT improved accessibility to fashion styles. There is no doubt internet and ICT brought out instant access to stock of information, product and services. This is what 21 (44\%) of the respondents affirmed. There are 17 (35\%) respondents who suggest that the use of ICT and 


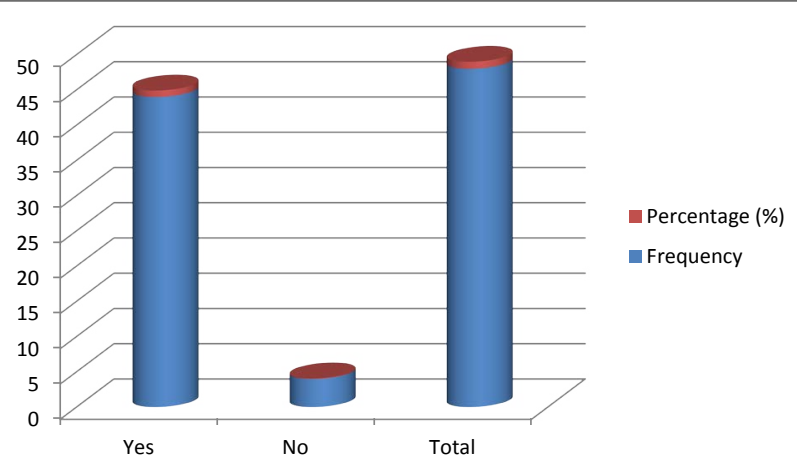

Figure 6: Status of improved access to fashion styles using ICTs and Internet.

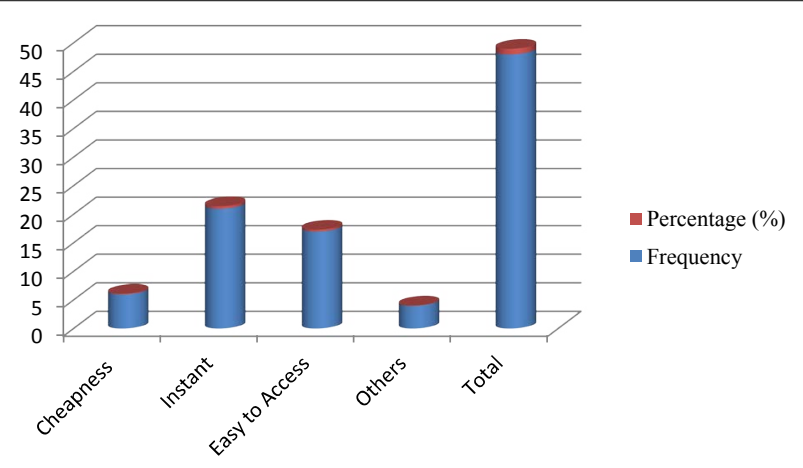

Figure 7: Areas of improvement.

internet have eased access to fashion styles while $6(13 \%)$ admit that it is cheap and last category believed there are other areas of improvement apart from aforementioned (Figure 8).

From the above, it is obvious that the respondents do not only surf the internet, browse and access the fashion styles but also adopt them for their daily social life. This is affirmed by 39 (81\%) respondents as indicated above. Only 9 (19\%) assert that they don't adopt the online fashion styles (Figure 9).

From the column above, 38 respondents agreed that there are enticements that encourage the adoption of online fashion styles. There are $16(42 \%)$ respondents who believed that they adopt online fashion styles because they are latest while 12 (32\%) held that the styles are modern. Other respondents who assume that better look and standard (quality) are their enticements constitute $7(18 \%)$ and $1(3 \%)$ respectively. There are $2(5 \%)$ that assume all the under listed as their enticements (Figure 10).

The table above indicates that, majority of the respondents most often and often adopts the fashion style they see on the social media and social networking site on the internet through ICT gadgets. This implies therefore that communication through the internet which appears to be the main attraction to them does not limit to access but also extended to adoption of online social life. According to argument of Gapsiso and Wilson [3] "the fact that we are in a globalised world makes internet appealing to these teenagers who are in their prime and are therefore enthusiastic about anything new that will enhance their process of communication". Under this analysis what internet offer does not limit to communication only but extended to change

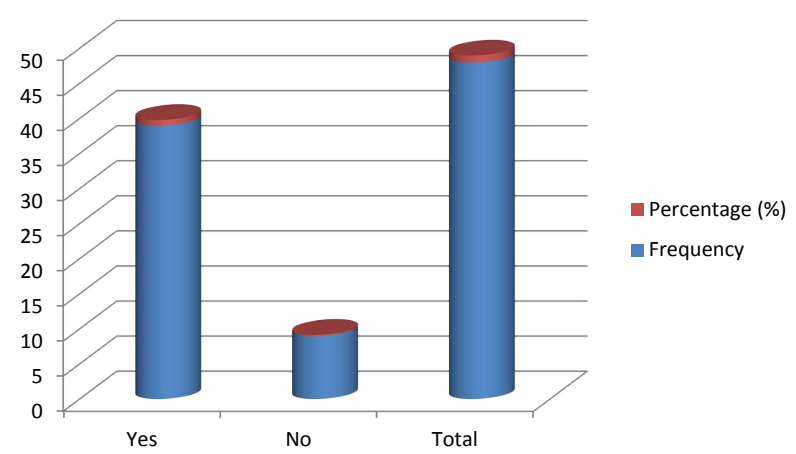

Figure 8: Do you adopt the fashion styles you access online?

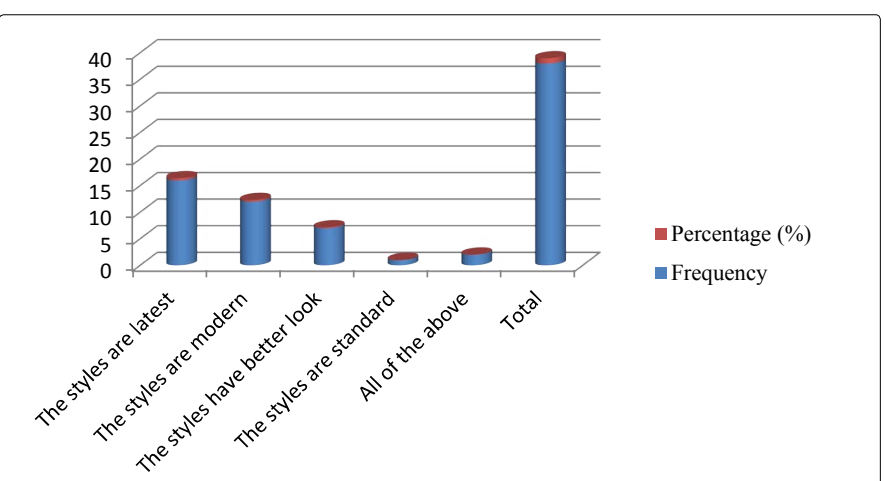

Note: Only 38 respondents answered this question because ten (10) respondents disqualify their response from the previous question. They identified that there are No enticements.

Figure 9: What are the enticements that led to changes in how you adopt fashion styles?

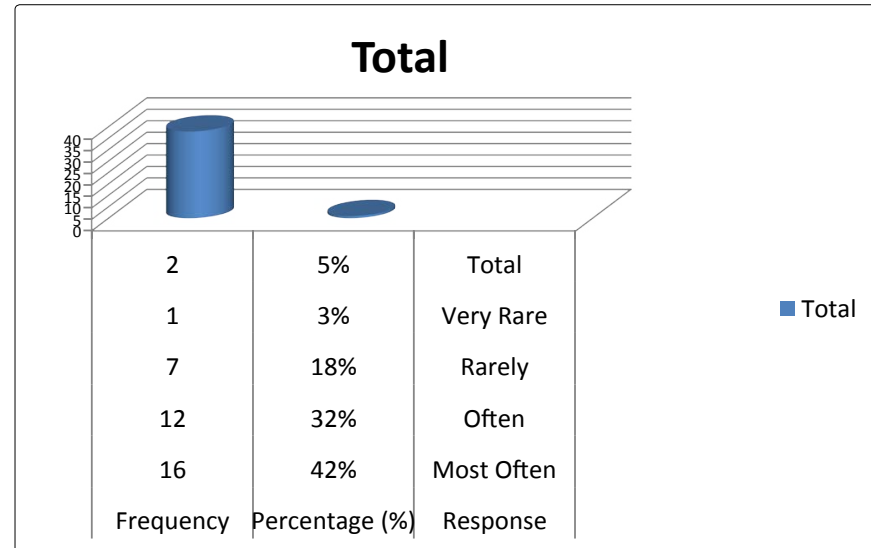

Figure 10: Frequency of adoption of online fashion styles.

in pattern of social life such as fashion styles, design and modeling (Figure 11).

The column above indicates that majority of the respondents succumb to the fact that the internet has reduced the desire of the respondents for offline fashion styles. This is in tandem with the position of Gapsiso and Wilson [3] that such happen owing to the fact that youth spend most of their time on the internet. However, the argument can be justified by the virtue of the fact that many have access 


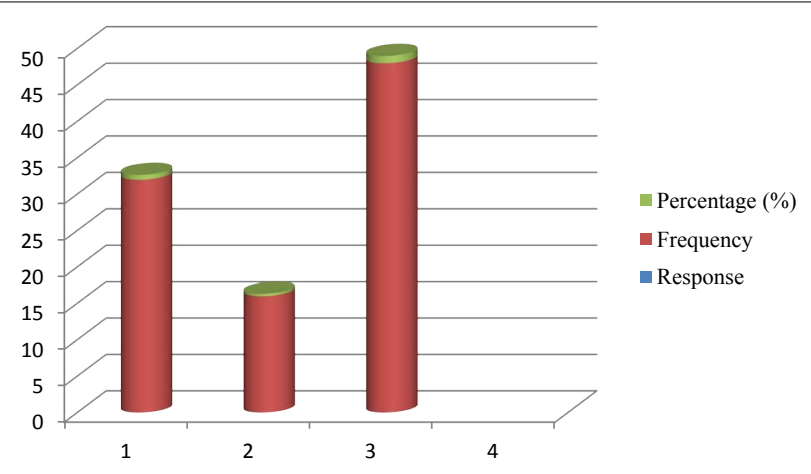

Figure 11: Has the use of ICT and internet decreased your desire for offline fashion styles?

to the internet on their mobile phones and therefore admire more product, services and people outside their immediate environment.

\section{Results and Discussion of Findings}

\section{Objective One: To find out whether the use of ICTs and} internet has improve people's access to fashion styles

The findings of this study indicated that the use of ICT and internet does not limit only to chat and interaction with friends online but also used for accessing desired product and services. Because of its invariable attributes of cheapness, instant and easy accessibility, it has improved access to the people's desire. This was reported by $92 \%$ of the respondents who believed that ICT has improved accessibility to various modern and qualitative fashion designs. The study found that ICT and internet has been accepted by the undergraduate students who are domicile in an academic environment presumed to be one of centers of civilization. These prompt quicker adoption of technologies and enthusiasm in accessing benefits and exploiting its dividends. This came in consonance with the argument of Gapsiso and Wilson who stated that internet has created a platform for youth to interact with friends and other people outside their communities especially through social media platforms. The study found that the social media platforms are drivers of the improvement in access to online fashion styles. This is because firms that are fully into fashion designs used the social media platform to advertise and publicise their designs and promote the sales of their products.

\section{Objective Two: To find out the channels through which people access fashion using ICTs and the internet}

The study found that there are channels through which youths access fashion styles using the internet. The channels are online-based. This is reported by $86 \%$ of the respondents who affirmed that there are online platforms where fashion styles and designs are found and that they access them for their consumption. Few number of the respondents indicated that there are no sites for fashion stuff. This constituted $14 \%$ of the respondents. Drawing from this, the study found that there are platforms dedicated for sharing and exchanging information about new fashion styles. This implies that easy access to internet and ICT has given the youths opportunity to explore forums, platforms, pages and other sites that provide latest styles of fashion product and services. The product include garment, shoes, necklaces, head ties, caps, glasses, wristwatches, shampoo, pomades, powder etc while services include pedicure, manicure, tattoo, hair styles, barbing styles etc.

The study found that two (2) social networking sites (Facebook and WhatsApp) constituted the highest percentage and most used platforms for accessing and sharing fashion stuff. There are 33\% and $36 \%$ of the respondents who affirmed that they use Facebook and WhatsApp respectively for accessing online fashion. Other social platforms such as Youtube, Twitter, Instagram follow with less number of users. This implies that Facebook and WhatsApp are the most admired platforms for accessing and sharing information on latest development online. This is because of their presumed cheapness, easy access and huge number of people on the platform. Blogs and others sites have negligible number. This entails that the youth hardly visit blogs to obtain latest news, design and styles of fashion. Even though there are fashion stylists who send out their designs and styles through these platforms.

\section{Objective three: To figure out if there are enticements that led to changes in how people adopt fashion styles}

The study found that youth adopt fashion styles they see online. This was found from remark of the $81 \%$ respondents who affirmed that after accessing the online fashion stuff, they further adopt them in their social life. It is the finding of the study that there are incentives that change the pattern of youths' adoption of fashion styles. There is no doubt that every community or society has its distinct fashion styles (operated offline) and civilization always leads to invention of new styles. Thus, the online platforms serve as chain for sharing of such distinct and new styles among different societies. This is encouraged by some incentives. The study found that the incentives include standard, quality, flashy and up-to-date. Greater number of the respondents affirmed to the fact that online fashion styles are latest which lured them to adopt them. Standard and better look of the fashion styles are what lured $18 \%$ and $3 \%$ of the respondents respectively. In this direction, the study also found that $5 \%$ of the respondents were attracted by more than enticement to adopt the online fashion styles.

\section{Objective four: To determine how often people access fashion styles using the ICTs}

The study found that, the youth spend much time accessing the internet thus, use such opportunities to access fashion styles. This was remarked by greater number of the respondents. This means that presence on internet incent the respondents to visit online fashion sites to get newest designs. It was also found that regularity of the users' presence on the internet as well as accessing the fashion sites differ. This tells about the nature, pattern of accessing fashion styles online. One can therefore argue that the number of sites internet user visit and the type of fashion style searching for, determine how often the user stay online and access such sites. The study also accessed how often the youth adopt the fashion styles they see online. It was found that the respondents regularly adopt the fashion styles online. This implies therefore that communication through the internet which appears to be the main attraction to them does not limit to access but also extended to adoption of online social life. According to argument of Gapsiso and Wilson (2015) "the fact that we are in a globalised world makes internet appealing to these teenagers who are in their prime and are therefore enthusiastic about anything new that will enhance their process of communication". Under this analysis what internet offer does not limit to communication only but extended to change in pattern of social life such as fashion styles, design and modeling.

Objective five: To determine whether the use of ICT and internet has decreased their desire for offline fashion style

From the study findings the respondents were classified into two; 
those who suggest that online presence and access to fashion styles virtually has decreased their desire for offline styles while other negate. The result of this open-ended question will thereby be presented in two sections. The first section presents response of those who agree to the question. To ensure accuracy the response were classified into categories. The first category of the respondents' remark that the fashion styles found online are up-to-date. Some of the comments are:

"Internet is more updated and involves many types of fashion styles"

"Because I grab the latest and modern styles in the internet"

"Most often offline fashion styles are awkward compared to internet design style"

"The offline fashion are not modernize"

"Because the fashion style from the internet are modern while those that are not from the internet are old fashion"

Some of the respondents remarked that the online sites give them access to numerous fashion styles and expand their knowledge of global fashion trend. Some of the remarks in this category affirmed that the youths do not only access them but also adopt them. Some of the remarks are:

"It increased my knowledge on fashion styles because I saw a lot of styles on the internet"

"The internet show us different fashion styles"

"The internet shows us more fashion trends of the modern world"

"Because I saw many styles in the internet and I grab them up"

"I valued the fashion styles I saw online than the offline"

The last category of the respondents asserts that the reason why they prefer online fashion styles and why it has decreased the desire for offline fashion is satisfaction. The remarks indicated that online styles are more fashionable. It was also asserted by some respondents that meeting new people, regular access to information and easy access as reasons for decreasing the desire for offline fashion. Some of the remarks are:

"Due to the kind of people I meet via social life"

"I became more of current"

"My access to regular information"
"Because we are always having our desire through online on the internet"

The study found here that the respondents have various reasons as to why online presence changes their preference for offline fashion. The reasons are verifiable from the attributes of online stuff, sites and results other research. It was also found that meeting new people from diverse background gives the user opportunity to share latest fashion styles and stay up-to-date. This has lured their attention away from the offline fashion.

\section{Conclusion}

The emergence of Information and Communication Technology has brought about a paradigm shift in how affairs of the society are being conducted. It has touched virtually all aspect of people life either social, political, economic. The social change being experienced is a product of the adoption of ICTs in people's accomplishments. The main conclusion drawn from the finding of the study is that ICT and the use of the internet have significantly changed the ways and pattern which youth's access and adopt fashion styles. The change was promoted by the activeness, presence, cheapness and instant nature of social networking sites available on the internet. It is also the conclusion of this study that the amount of time spent using the internet has greater influence on the decreasing desire for offline fashion styles among youths.

\section{References}

1. Igbo HI, Egbe-Okpenge EG, Awopetu RG (2013) Influence of information and communication technology on behavior problem of Nigerian youth. Social and Behavioural Sciences 84: 2-10

2. Wilterdink WN (2017). Social change. Encyclopedia Britanica Inc.

3. Gapsiso ND, Wilson J (2015) The impact of the internet on teenagers' face-toface communication. Journal of Studies in Social Sciences 13: 2-19.

4. Dewing M (2010) Social media: An introduction. Ottawa: Library of Parliament

5. Kwolton T (2012) Twitter passes 500 million users, study reveals: Canada accounts for $2 \%$ of all users. TechVibes

6. Danah B (2009) Social media is here to stay........Now what? Lecture notes, Microsoft Research Tech Fest; Washington.

7. David G (2009) Blogs that spin a web of deception. The Financial Times.

8. Shah S (2017) Theories of social change: Meaning, nature and processes Sociology discussion.

9. Overby EM (2008) Process virtualization theory and the impact of information technology. Organization science 19: 277-291. 